\title{
Thermally irreversible photochromic dithienylethenes
}

\author{
M. M. Krayushkin, ${ }^{1 \dagger}$ B. M. Uzhinov, ${ }^{2 \ddagger}$ A. Yu. Martynkin, ${ }^{1}$ D. L. Dzhavadov, ${ }^{1}$ \\ M. A. Kalik, ${ }^{1}$ V. L. Ivanov, ${ }^{2}$ F. M. Stoyanovich, ${ }^{1}$ L. D. Uzhinova, ${ }^{2}$ \\ and O. Yu. Zolotarskaya ${ }^{1}$ \\ ${ }^{1}$ N. D. Zelinsky Institute of Organic Chemistry, Leninsky prospect, 47, Moscow, 117913, Russia \\ ${ }^{2}$ M. V. Lomonosov Moscow State University, Chemistry Department, Vorob'evy Gory, Moscow, 119899, Russia
}

\begin{abstract}
A lot of previously unknown derivatives of dithienylperfluorocyclopentene (DTPFCP) were synthesized. It was shown that 2,2'-dialkylsubstituted DTPFCP'S are phtochromes. The quantum yields of forward and backward photochemical reactions and spectral parameters of open and cyclic forms of the photochromes synthesized were measured. An attempt to obtain fluorescing phtochromes by means of introduction of benzoxazolyl, benzthiazolyl and 1,2,4-oxadiazolyl moieties in 5 and $5^{\prime}$ positions of DTPFCP failed; these compounds were synthesized but they do not fluoresce.
\end{abstract}

\section{INTRODUCTION}

Dithienylethenes are studied during last years as photochromes very actively [1]. Previously unknown alkylthio- or alkylsulphonyl derivatives of dithienylethenes as well as dithienylethenes with heterocycles as potential fluorophoric fragments are the objects of this study.
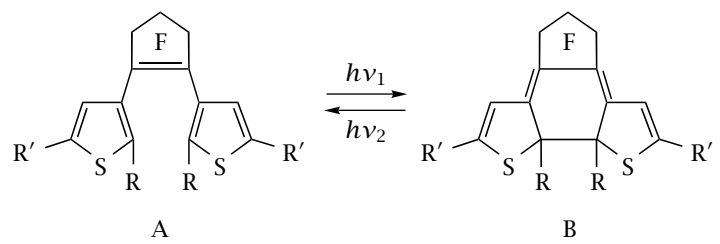

It is known that alkylthio groups activate thiophene ring strongly in the reaction of electrophilic substitution and metallation. These groups promote substantially the introduction of various functional substituents into free positions of the heterocycle and allow one to create fused systems based on thiophene with longer chains of conjugation.

The introduction of "fluorophoric" substituents can help to solve the problem of the read out without essential effect on interconversion of cyclic and open forms of dithienylethene photochromes.

\section{SYNTHESIS OF DITHIENYLETHENES}

Synthesis of compounds with sulphur containing groups in positions 2 of thiophene rings was conducted according to Scheme 1 starting from 2ethylthiothiophene.

The bromination of the latter and further debromination of dibromosulphide II at $-70^{\circ} \mathrm{C}$ result in 3 bromo-2-ethylthiothiophene III in a good yield. Bissulphide I was synthesized in the yield $60 \%$ by the successive action of BuLi and octafluorocyclopentene on bromide III in ether. The compound I is

† E-mail: mkray@ioc.ac.ru,

‡ E-mail: uzhinov@light.chem.msu.su transformed quantitatively into bis-sulphone IV by the action of excess $30 \% \mathrm{H}_{2} \mathrm{O}_{2}$. Bis-sulphide I is easily metallated by BuLi in ether during several minutes into either thiophene cycles and then after the treatment by DMF or $\mathrm{CO}_{2}$ is transformed in good yields into dialdehyde $\mathrm{V}$ or into dicarboxylic acid VI, respectively.

The use of 5-ethylthio-2-ethylthiophene VII (Scheme 2) as starting compound enables to obtain not only alkylated analogs of I and IV, but also their isomers with sulphur-containing groups in position 5 of thiophene cycles.

Dibromide VIII is formed in high yield by the bromination of sulphide VII using two equivalents of $\mathrm{Br}_{2}$ in glacial AcOH. The treatment of VIII with one equivalent of BuLi in $\mathrm{Et}_{2} \mathrm{O}$ results in the mixture of isomeric monobromides IX and $X$ in the ratio $\sim 1: 4$. The pure 3-bromo-5-ethylthio-2-ethylthiophene $\mathrm{X}$ was isolated by column chromatography and it was used for further synthesis. Isomeric 1,2-bis(2-ethyl-5-ethylthio-3thienyl)hexafluorocyclopentene XI and 1,2-bis(5-ethyl2-ethylthio-3-thienyl)hexafluorocyclopentene XII were obtained by successive action of BuLi and octafluorocyclopentene at $-70{ }^{\circ} \mathrm{C}$ on monobromides X and IX, respectively. Isomers XI and XII were oxidized with 30\% $\mathrm{H}_{2} \mathrm{O}_{2}$ into corresponding bis-sulphones XIII and XIV.

Alternative method to obtain the dithienylethene XI starting with 2-ethylthiophene was also proposed (Scheme 3).

This approach allows to obtain $\mathrm{X}$ in $75 \%$ yield This compound is necessary for synthesis of XI and which does not contain isomeric 4-bromo-5-ethylthio2-ethylthiophene (in contrast to methods shown in Scheme 2). The compound XI is easily brominated with 2 equivalents of $\mathrm{Br}_{2}$ in chloroform or with bromidebromate mixture quantitatively into dibromide $\mathrm{XV}$, which is transformed into bis-sulphone XVI by oxidation with $40 \% \mathrm{H}_{2} \mathrm{O}_{2}$ in AcOH. Dicarboxylic acid XVII is formed in $70 \%$ yield by the interaction between $\mathrm{XV}$ and BuLi in $\mathrm{Et}_{2} \mathrm{O}$ with subsequent carbonization.

As it was stated in [2], reading out can be realized by means of fluorescence excited in the spectral region 


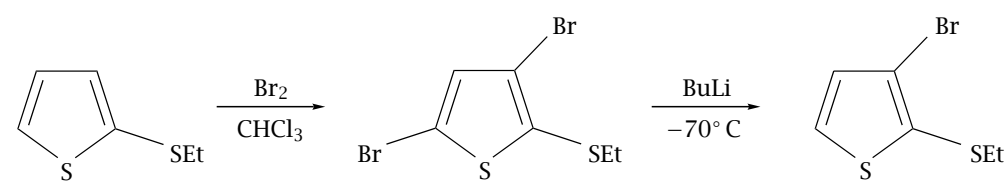

II

III
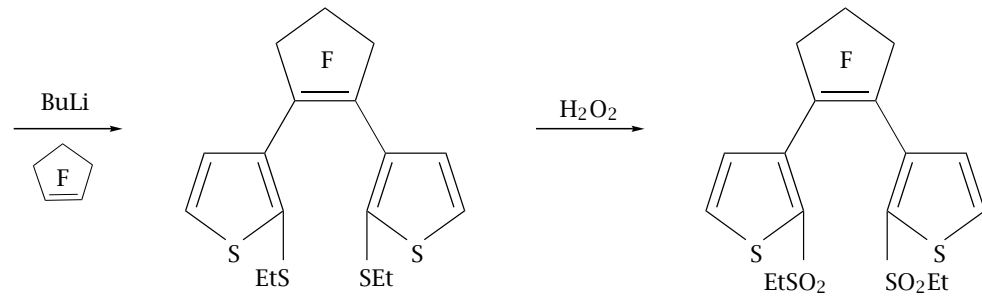

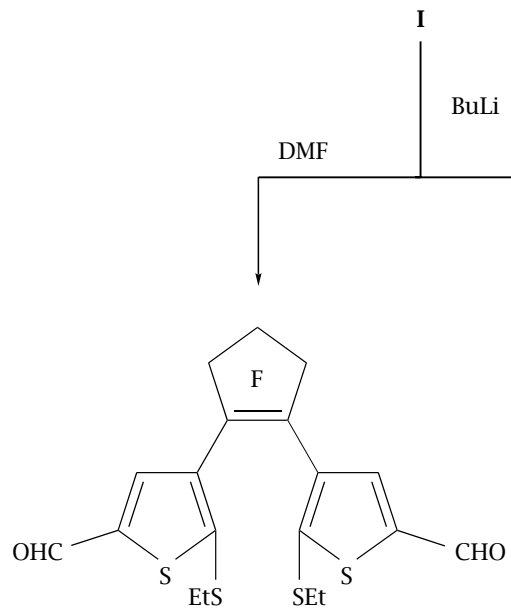

V

uLi
IV

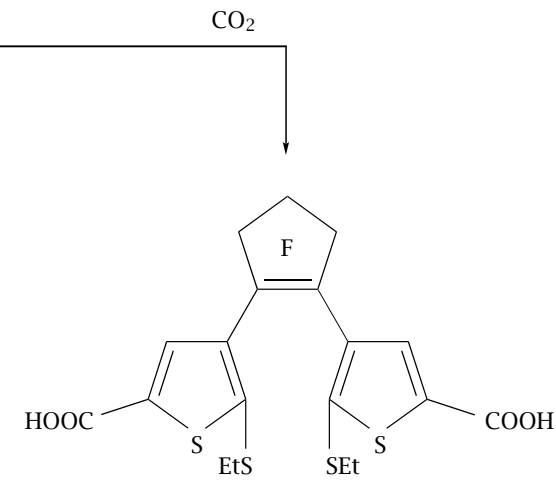

VI

Scheme 1

where the interconversion of two dithienylethenes is absent. The synthesis of the compounds containing potential "fluorophor" fragments to provide fluorescing photochromes was performed to create the substances with properties stated above. Benzoxazole cycle, benzthiazole cycle and aryl derivatives 1,3,4oxadiazole were chosen as such fragments. Recall for instance that 2,5-bis(2-benzoxazolyl)thiophene is used as fluorophor [3]. 1,2-Bis[5-(2-benzoxazolyl)-2-methyl3-thienyl]hexafluorocyclopentene XXIII was obtained according to the Scheme 4 .

2-(4-Bromo-5-methyl-2-thienyl)benzoxazole XIX was formed using condensation of 4-bromo-5-methyl-2thiophenecarboxylic acid XX with $o$-aminophenol in xylene in the presence of $\mathrm{H}_{3} \mathrm{BO}_{3}$ in $45 \%$ yield. The exchange of $\mathrm{Br}$ for $\mathrm{Li}$ in bromide XIX under the action of BuLi at $-70^{\circ} \mathrm{C}$ resulted in Li-derivative XXI. The interaction of XXI with octafluorocyclopentene resulted in the adduct XXII ( $49 \%$ yield). The interaction of this adduct with Li-derivative XXI resulted in the product XXIII in $31 \%$ yield. The acid XX was the starting compound also in the preparation of the benzthiazole photochrome XXV according to Scheme 5.
2-(4-Bromo-5-methyl-2-thienyl)benzthiazole XXIV was synthesized by successive interaction of thiophenecarboxylic acid XX with $\mathrm{SOCl}_{2}$ and $o$ aminothiophenol in $79 \%$ yield. The reaction of XXIV with BuLi at $-70{ }^{\circ} \mathrm{C}$ results the Li-derivative, which interacts with octafluorocyclopentene to give XXV in 23\% yield. The photochromes, 1,2-bis [2-methyl-5-(5-phenyl1,3,4-oxadiazolyl-2)-thienyl-3] hexafluorocyclopentene XXIXa and 1,2-bis[2-methyl-5-[5-(4-methoxyphenyl)1,3,4-oxadiazolyl-2)-thienyl-3]hexafluorocyclopentene XXIXb were synthesized according to Scheme 6 .

5-Aryl-2-(2-thienyl)-1,3,4-oxadiazoles XXVIIIa,b were obtained by cyclization of 1-aroyl-2-(5-methyl-4-bromo2-thienyl)hydrazines XXVIIa,b in phosphorus chloroxide in 61 and $70 \%$ yields, respectively. XXVIIa,b were synthesized by the interaction 4-bromo-5-methyl-2thiophenecarboxhydrazide XXVI with of benzoyl and $p$-methoxybenzoyl chlorides, respectively. Compounds XXIXa,b were obtained by the treatment of bromides XXVIIIa,b with BuLi and subsequent interaction with octafluorocyclopentene in 34 and 30\% yield, respectively. 

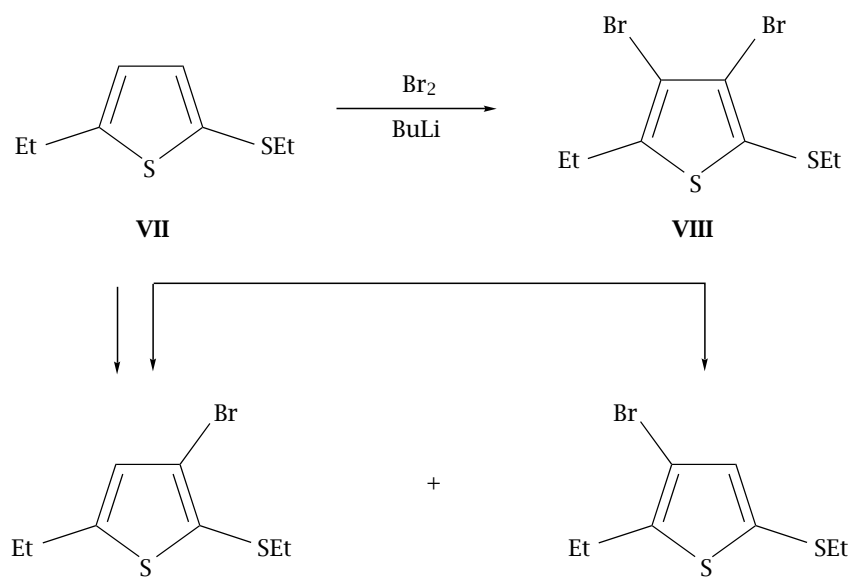

IX (20\%)

X (80\%)
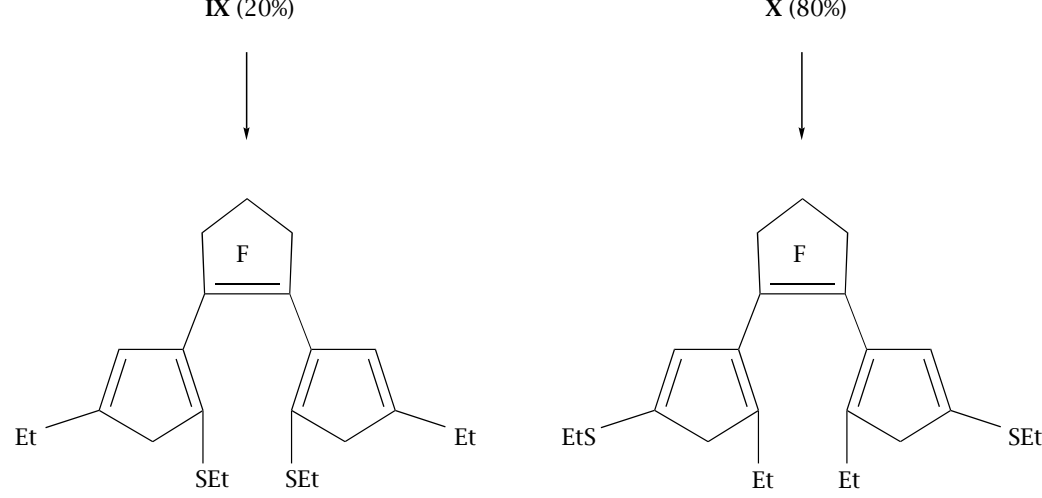

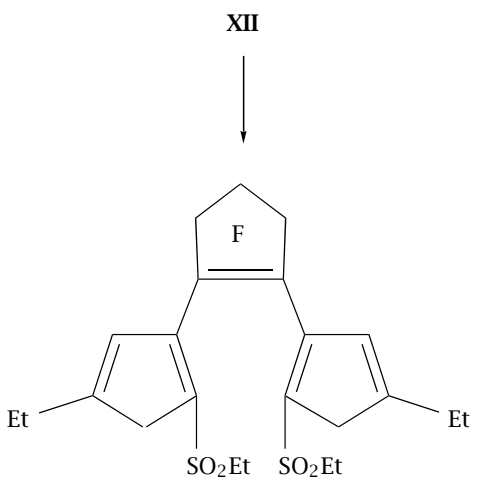

XIV

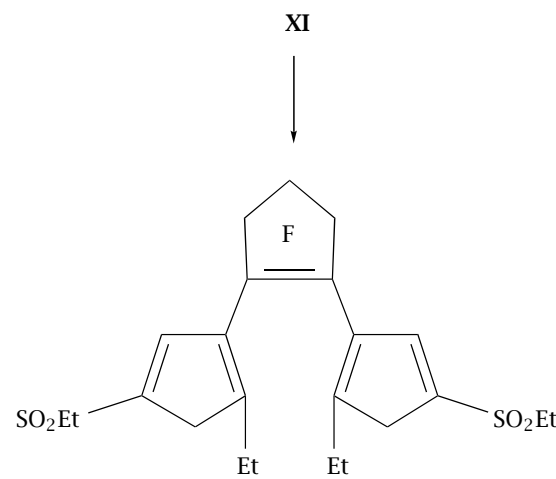

XIII

Scheme 2

\section{PHOTOCHROMISM OF DITHIENYLETHENES}

The study of photochromic properties of synthesized dithienylethenes has been shown that the compounds XI, XIII, XV, XVI, XVII, XVIII, XXIII, XXV, XXIXa and XXIXb are photochromes. In the case of compounds bearing in 5 and $5^{\prime}$ positions other than sulphonyl one (that is XI, XV, XVII, XVIII, XXIII, XXV, XXIXa and XXIXb) colourless open form $\mathrm{A}$ is transformed into coloured cyclic form $B$ under the irradiation of these compounds in ethanol by UV-light $(\lambda=313 \mathrm{~nm})$. Decrease of optical density at the maximum of absorption spectrum of form A and increase of optical density at the maximum of absorption spectrum of form B are observed. Under irradiation of ethanolic solution, containing B form, by the light with wavelength 546 or $578 \mathrm{~nm}$ decrease of optical density at the maximum of absorption spectrum of form $B$ and increase of optical density at the maximum of absorption spectrum of form A are observed (Figures 1, 2, 3, $4,5,6,7)$. The complete transformation $\mathrm{A} \rightarrow \mathrm{B}$ does not take place because of overlapping of absorption spectra of $\mathrm{A}$ and $\mathrm{B}$ forms at $\lambda=313 \mathrm{~nm}$. At some irradiation doze the photostationary state is established, that is, the rates of forward and backward photoreactions are equal and the concentrations of both forms of photochromic compounds under further irradiation 

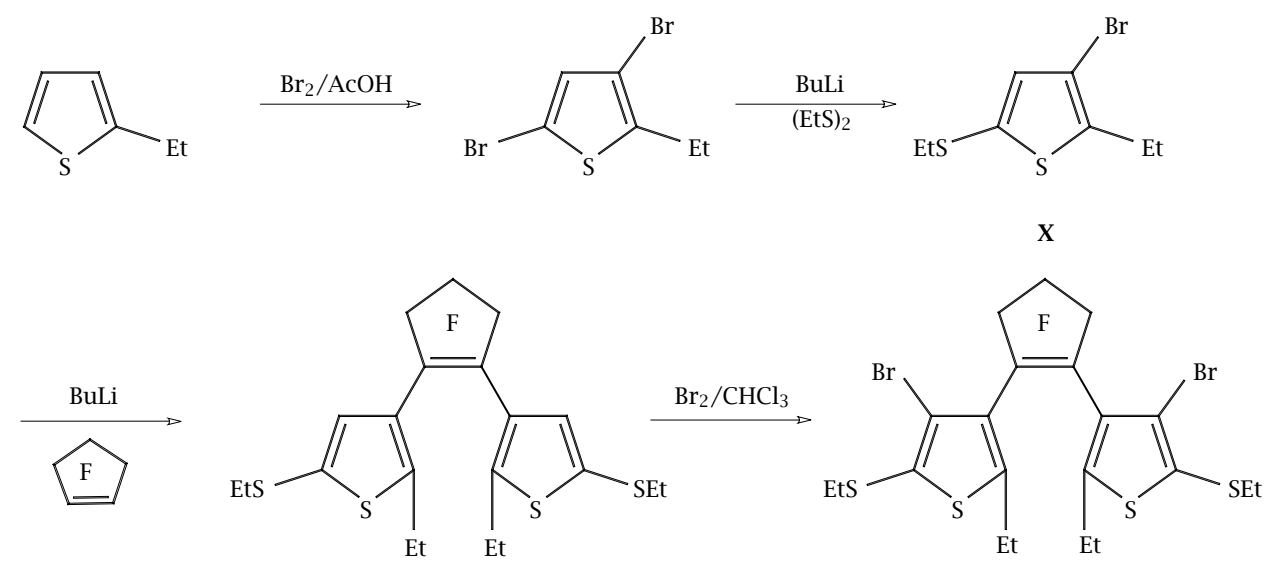

XV

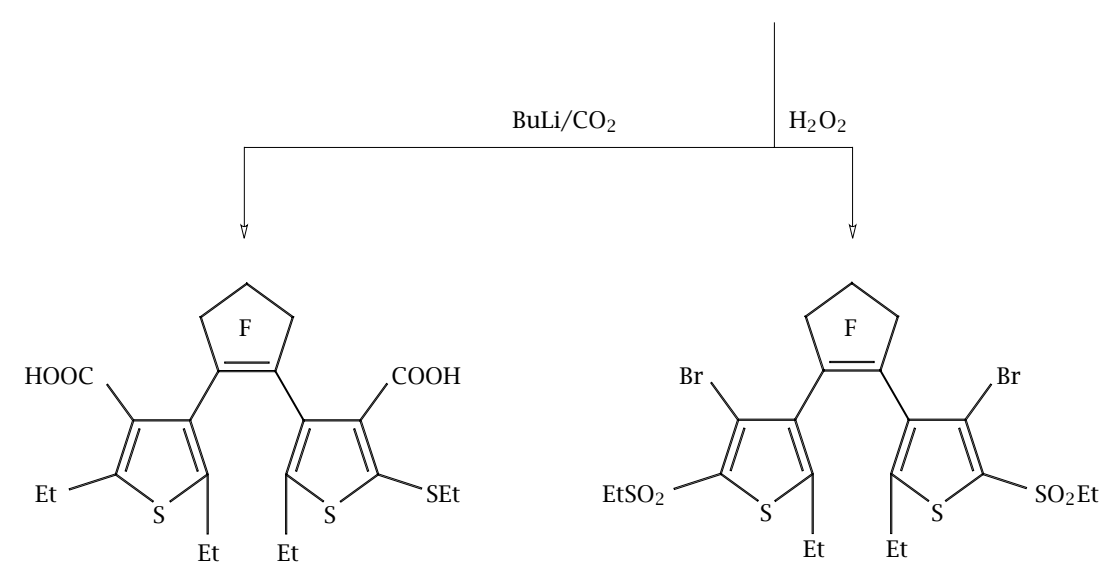<smiles>[Z11]c1sc(C(C)=O)c(C2=C(c3c(CC)sc(CC)c3C(C)=O)CCC2)c1C(=O)OC</smiles>

XVI

XVIII

Scheme 3

are not changed. The ratio of concentrations of A and B forms in the photostationary state depends on irradiation wavelength and inversely proportional to the ratio of extinction coefficients of these forms at certain wavelength.

The isosbestic points in absorption spectra of solution of these photochromic compounds are observed. The coincidence of their position for forward and backward reactions testifies the complete photoreversibility of photocyclization and the absence of side processes.
The dark reaction $\mathrm{A} \rightarrow \mathrm{B}$ is absent, the dark reaction $\mathrm{B} \rightarrow \mathrm{A}$ is also absent. The quantum yields of forward and backward phtochemical reactions and spectral data of open and cyclic forms are given in Table 1.

For 5, 5'-disulphonyl substituted dithienylethenes XIII and XVI the formation of coloured form B, accompanied by the decrease of the optical density at the absorption maximum of $\mathrm{A}$, is observed under the irradiation of ethanolic solutions with UV-light $(\lambda=313 \mathrm{~nm})$. However, under the subsequent irradiation of these 
<smiles>Cc1sc(-c2nc3ccccc3o2)cc1Br</smiles>

XIX<smiles>Cc1sc(-c2nc3ccccc3o2)cc1[Hg]</smiles>

XXI
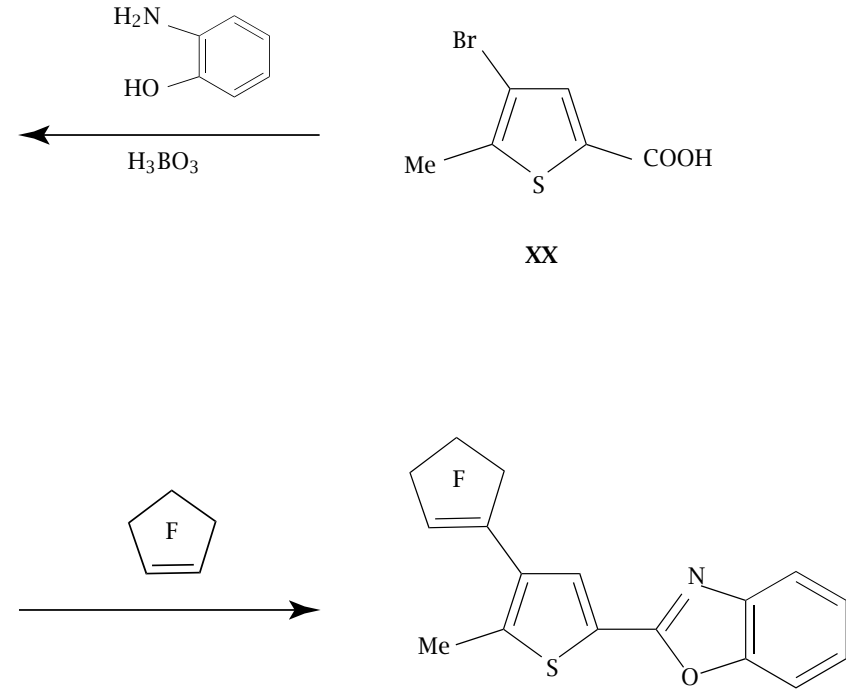

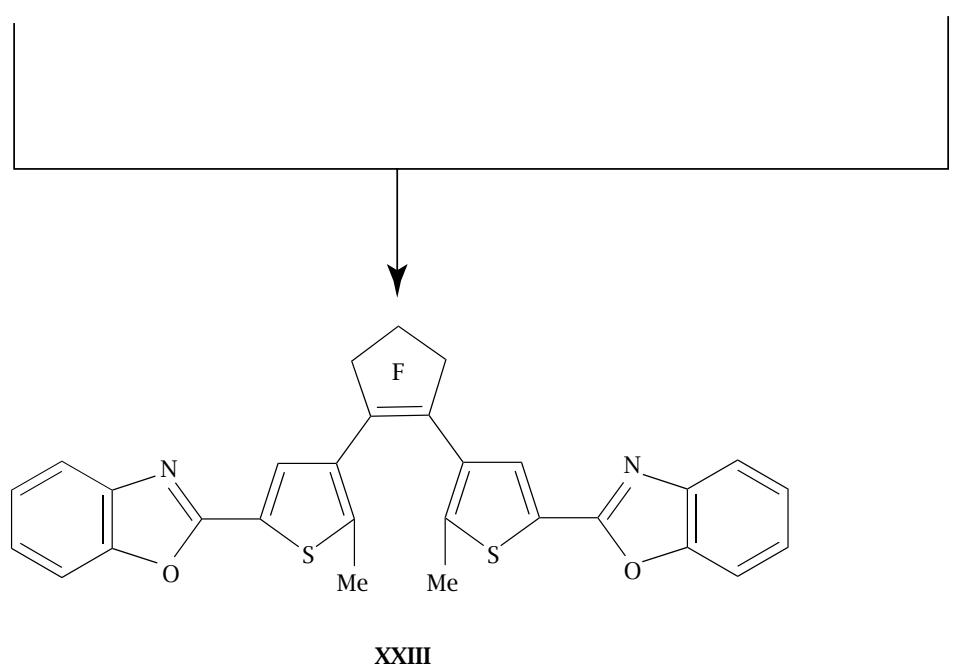

Scheme 4

solutions with the light of $\lambda=578 \mathrm{~nm}$ the isosbestic points in the absorption spectra of the solutions are not observed (Figures 8 and 9). It proves that photochromic reactions of compounds XIII and XVI are accompanied by some other transformations which are not related with photocyclization.
XXII<smiles>Cc1sc(C(=O)O)cc1Br</smiles>

$\mathrm{XX}$

Table 1. The quantum yields of forward and backward photochemical reactions and spectral data of open and cyclic forms of photochromic dithienylperfluorocyclopentenes.

\begin{tabular}{llllc}
\hline \multirow{2}{*}{ Compound } & \multicolumn{2}{c}{$\lambda_{\max }, \mathrm{nm}\left(\varepsilon, \mathrm{M}^{-1} \mathrm{~cm}^{-1}\right)$} & \multicolumn{2}{c}{ The quantum yield of photoreaction $\Phi$} \\
\cline { 2 - 5 } & Open form & Cyclic form & $\Phi_{A \rightarrow B}$ & $\Phi_{B \rightarrow A}$ \\
\hline XI & $243(24500)$ & $563.5(18700)$ & 0.14 & 0.01 \\
XV & $249(16500)$ & $592(5350)$ & 1.0 & 0.04 \\
XVII & $305(1200)$ & $568(7930)$ & 0.80 & 0.02 \\
XXIII & $324.5(45900)$ & $618.5(25200)$ & 1.0 & 0.006 \\
XXV & $260(51600)$ & $633(21600)$ & 0.84 & 0.004 \\
XXIX $_{\mathrm{a}}$ & $310.5(48700)$ & $602(14600)$ & 1.0 & 0.014 \\
XXIX $_{\mathrm{b}}$ & $317(52700)$ & $604.5(19300)$ & 0.85 & 0.01 \\
\hline
\end{tabular}

The dithienylethenes, containing alkylthio- or alkylsulphonyl groups in positions 2 of thiophene cycles, but not alkyl ones (i.e. I, IV, V, VI, XII and XIV) do not change their absorption spectra under UV-irradiation $(\lambda=313 \mathrm{~nm})$, that is, they are not photochromes.

We have studied the fluorescence properties of 


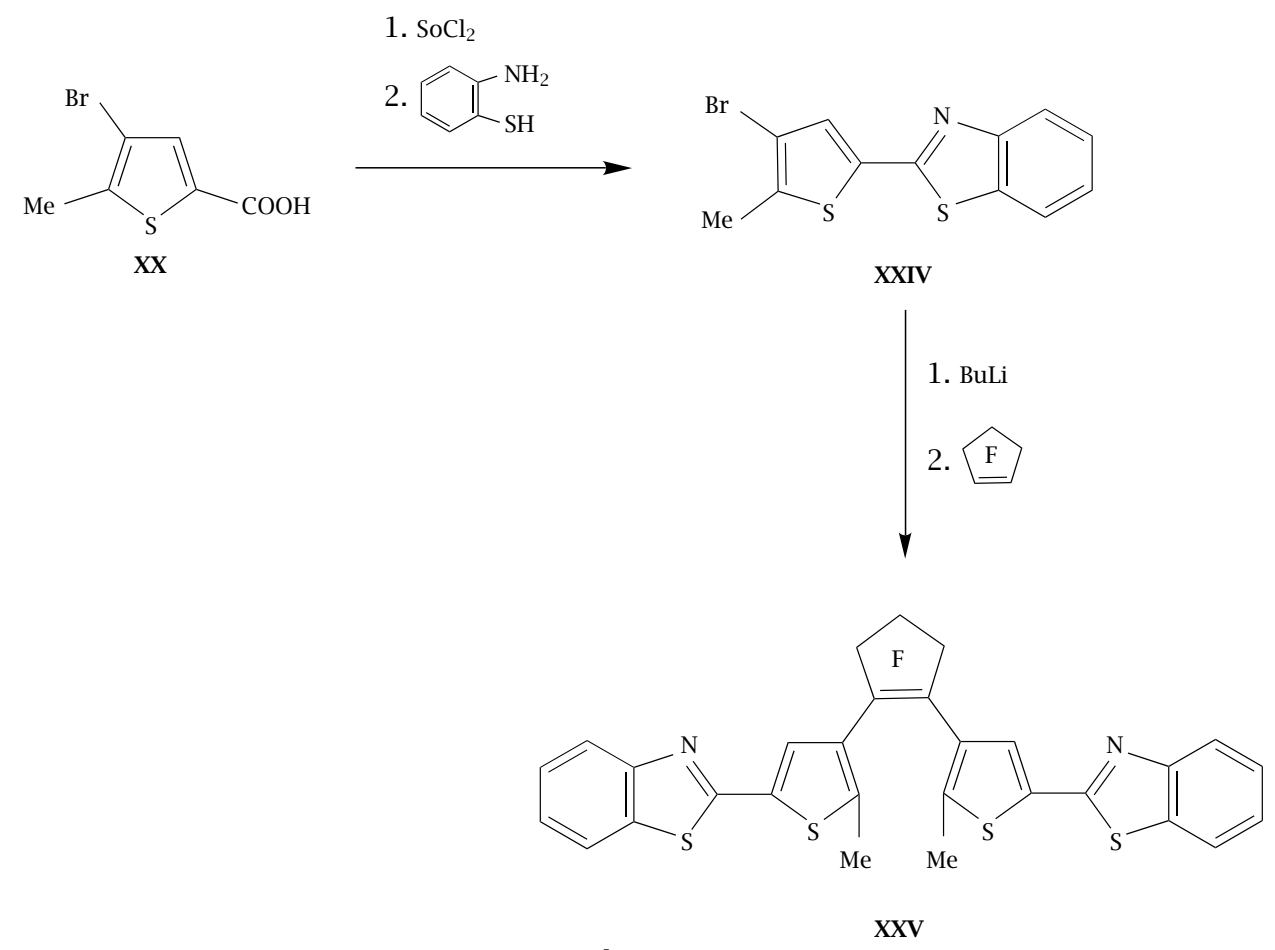

Scheme 5

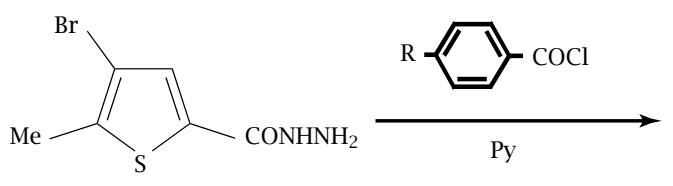

XX

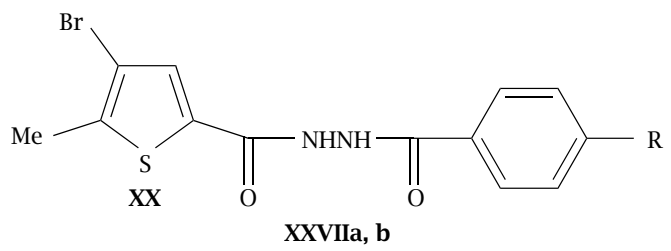

XXVI

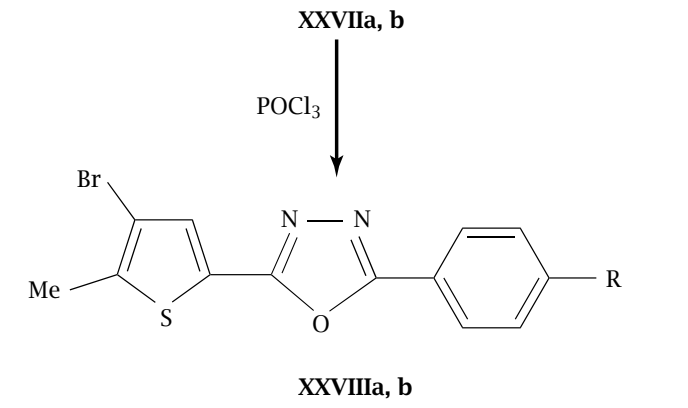
1. BuLi
2. $\mathrm{F}$

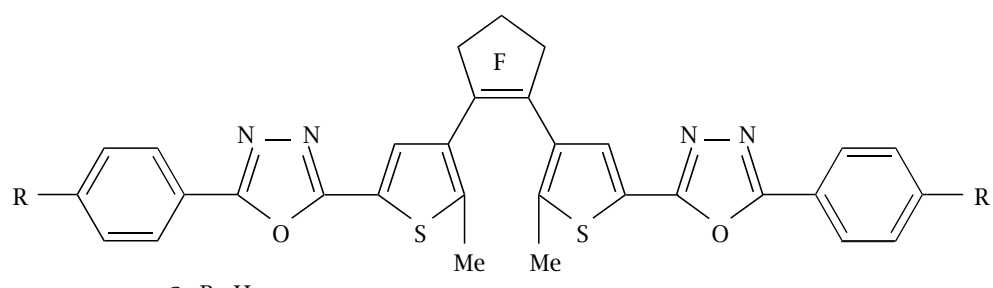

a. $\mathrm{R}=\mathrm{H}$ XXIXa,b

a. $\mathrm{R}=\mathrm{H}$
b. $\mathrm{R}=\mathrm{OCH}_{3}$

Scheme 6 


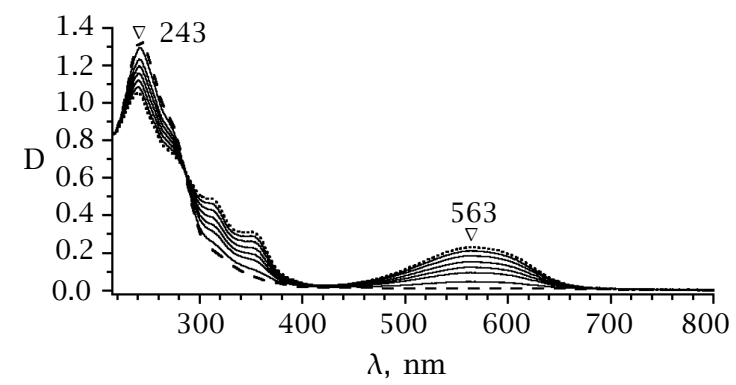

Figure 1. The change of the absorption spectra of XI under $U V$-irradiation $(\lambda=313 \mathrm{~nm})$.

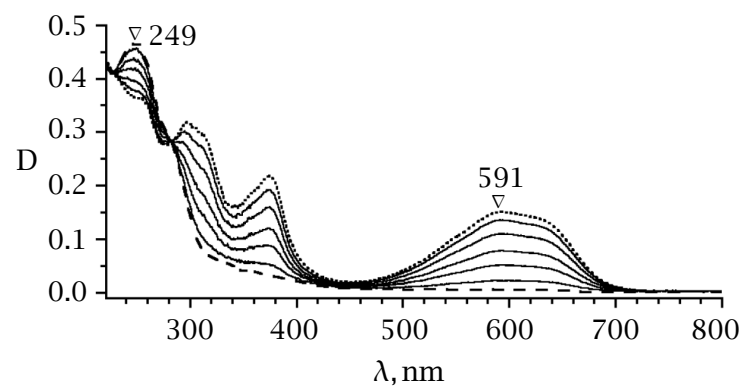

Figure 2. The change of the absorption spectra of $X V$ under $U V$-irradiation $(\lambda=313 \mathrm{~nm})$.

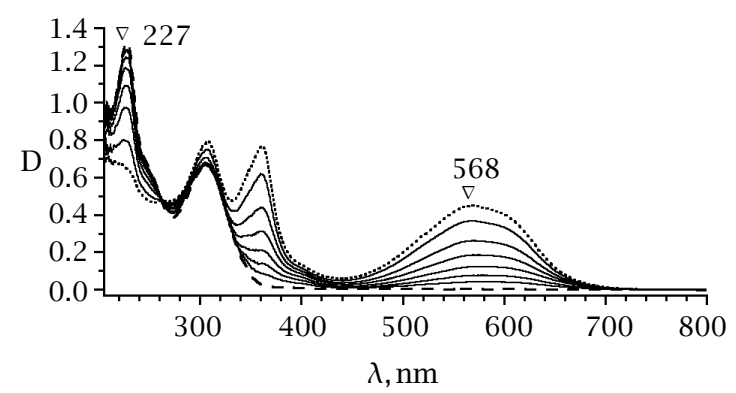

Figure 3. The change of the absorption spectra of XVII under UV-irradiation $(\lambda=313 \mathrm{~nm})$.

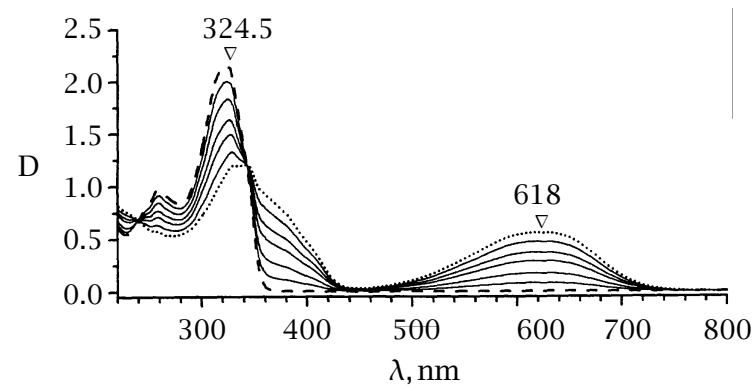

Figure 4. The change of the absorption spectra of XXIII under UV-irradiation $(\lambda=313 \mathrm{~nm})$.

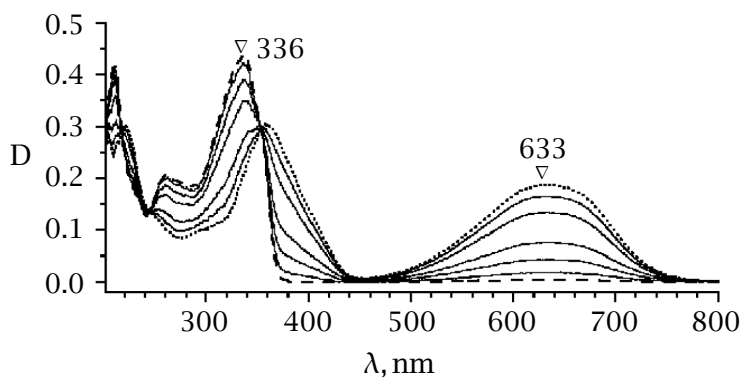

Figure 5. The change of the absorption spectra of XXV under UV-irradiation $(\lambda=313 \mathrm{~nm})$.

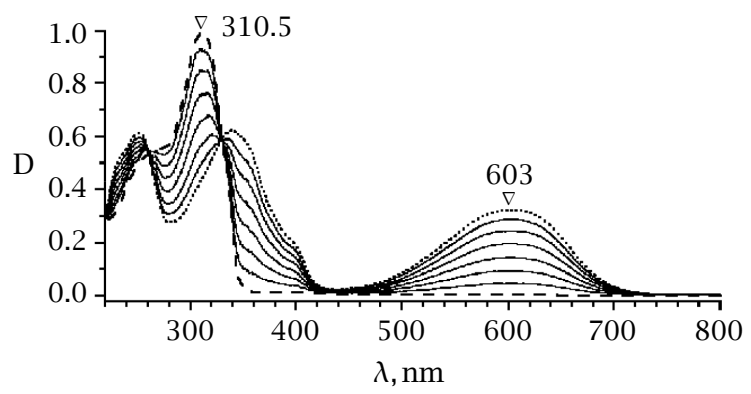

Figure 6. The change of the absorption spectra of XXIXa under $U V$-irradiation $(\lambda=313 \mathrm{~nm})$.

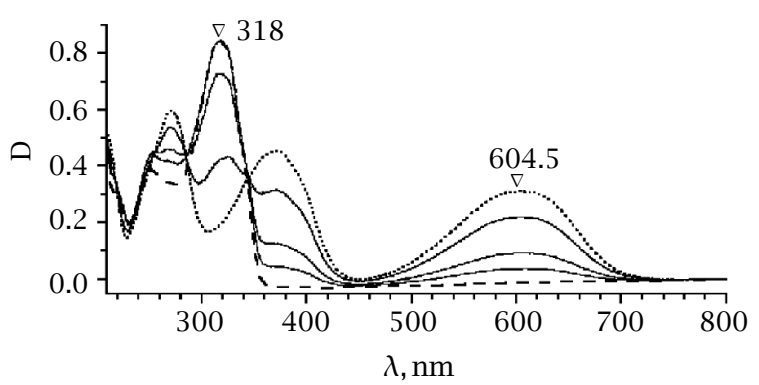

Figure 7. The change of the absorption spectra of XXIX under UV-irradiation $(\lambda=313 \mathrm{~nm})$.

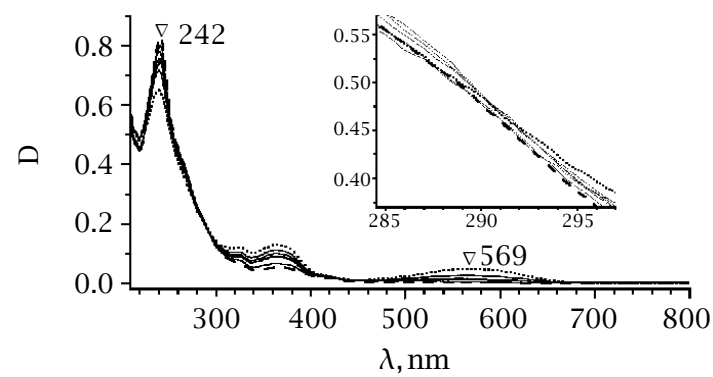

Figure 8. The change of the absorption spectra of XIII under UV-irradiation $(\lambda=313 \mathrm{~nm})$. 


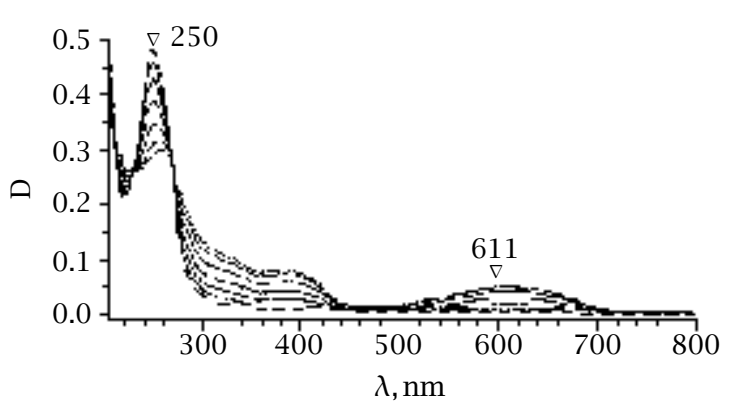

Figure 9. The change of the absorption spectra of XVI under UV-irradiation $(\lambda=313 \mathrm{~nm})$.

compounds XVIII, XXV, XXIXa and XXIXb whose structures contain "fluorophor" fragments. Unfortunately, these compounds do not fluoresce neither in open nor in cyclic form.

\section{EXPERIMENTAL PART}

The irradiation of samples was conducted with resonance mercury lamp $(\lambda=254 \mathrm{~nm})$ and mercury lamp DRSh-500 supplied with filters for selection of mercury spectrum lines at wavelengths 313,546 and $578 \mathrm{~nm}$. The intensity of DRSh-500 irradiation was measured by means of photocell F4, calibrated by ferrioxalate actinometer [4] for $\lambda=313 \mathrm{~nm}$ and $\lambda=546 \mathrm{~nm}$ and actinometer based on Reynecke salt [5] for $\lambda=578 \mathrm{~nm}$. Absorption spectra were registered by spectrophotometer "Shimadzu-2101PC". The fluorescence was studied by means of spectrofluorimeter "Perkin-Elmer LS-50".

To determine the quantum yields of forward and backward reactions the ethanolic solution of a substance was irradiated with the light $\lambda=313 \mathrm{~nm}$ (forward reaction) and $\lambda=546 \mathrm{~nm}$ or $\lambda=578 \mathrm{~nm}$ (backward reaction). The duration of irradiation was varied from $5 \mathrm{~s}$ till 1-2 $\min$ (7-10 experimental points). The absorption spectrum of irradiated solution was registered after each exposition.

The quantum yield $(\Phi)$ was calculated by means of the following equation

$$
\Phi=\frac{V \Delta D^{\mathrm{B}}(t)}{\left(\varepsilon^{\mathrm{B}} l J_{\mathrm{abs}}(t)\right)},
$$

where $V$ - the volume of irradiated solution, $\Delta D^{\mathrm{B}}(t)$ - the change of solution optical density at absorption spectrum maximum of B during time $t, \varepsilon^{\mathrm{B}}$-extinction coefficient of $\mathrm{B}, l$-the length of optical way, $J_{\mathrm{abs}}(t)$ - the quantity of light, absorbed by the solution during time $t$. For backward reaction the dependence of $\Delta D^{\mathrm{B}}(t)$ on $J_{\mathrm{abs}}(t)$ is linear, therefore $\Delta D^{\mathrm{B}}(t) / J_{\mathrm{abs}}(t)=$ const and thus $\Phi$ does not depend on $t$; for forward reaction $\Delta D^{\mathrm{B}}(t) / J_{\mathrm{abs}}(t)$ was determined as the tangent of the slope to the curve $\Delta D^{\mathrm{B}}(t)-J_{\mathrm{abs}}(t)$ at the origin of the coordinates.

To calculate the extinction coefficient of $\mathrm{B}\left(\varepsilon^{\mathrm{B}}\right)$ it was supposed that at small expositions (small conversions) the contribution of $\mathrm{B}$ absorption is negligible small. Then

$$
C^{\mathrm{B}}(t)=C^{\mathrm{A}}\left(t_{0}\right)-C^{\mathrm{A}}(t)=\frac{D^{\mathrm{A}}\left(t_{0}\right)-D^{\mathrm{A}}(t)}{\varepsilon^{\mathrm{A}} l}=\frac{\Delta D^{\mathrm{A}}(t)}{\varepsilon^{\mathrm{A}} l},
$$

where $C^{\mathrm{A}}(t)$ and $C^{\mathrm{B}}(t)$-the molar concentrations of $\mathrm{A}$ and $\mathrm{B}$, respectively, after the irradiation during time $t$, $C^{\mathrm{A}}\left(t_{0}\right)$-the molar concentration of A in non-irradiated solution, $D^{\mathrm{A}}(t)$-the optical density of the solution after the irradiation during time $t, D^{\mathrm{A}}\left(t_{0}\right)$-the optical density of non-irradiated solution at the maximum of absorption spectrum of A. By substituting of the expression for $C^{\mathrm{B}}(t)$ into the equation $\varepsilon^{\mathrm{B}}=D^{\mathrm{B}} /\left(C^{\mathrm{B}} l\right)$ we get $\varepsilon^{\mathrm{B}}=\varepsilon^{\mathrm{A}} D^{\mathrm{B}}(t) / \Delta D^{\mathrm{A}}(t)$.

The quantity of the absorbed light $\left(J_{\mathrm{abs}}\right)$ was determined by means of equation

$$
J_{\mathrm{abs}}=J_{0} \int_{0}^{t}\left(1-10^{-D_{\lambda}}\right) d t=J_{0} \sum_{\Delta t}\left(1-10^{-\overline{D_{\lambda}(\Delta t)}}\right) \Delta t,
$$

where $J_{0}$-the light intensity at the irradiation wavelength, $D_{\lambda}$-the optical density of the solution at the irradiation wavelength.

\section{REFERENCES}

[1] M. Irie and K. Uchida, Bull. Chem. Soc. Jpn. 71 (1998), 985.

[2] G. H. Tsvigoulis and J.-M. Lehn, Chem. Eur. J. 2 (1996), 1399.

[3] L. I. Belen'kii, E. P. Zakharov, M. A. Kalik, V. P. Litvinov, F. M. Stoyanovich, S. Z. Taits, and B. P. Fabrichnyi, Novye napravleniya $\mathrm{v}$ khimii tiofena (New trends in thiophene chemistry) (Ya. L. Gol'dfarb, ed.), Nauka, Moscow, 1976, p. 11.

[4] C. B. Hatchard and C. A. Parker, Proc. Roy. Soc., vol. A235, 1956, p. 518.

[5] E. W. Wagner and A. W. Adamson, J. Am. Chem. Soc. 88 (1966), 394. 


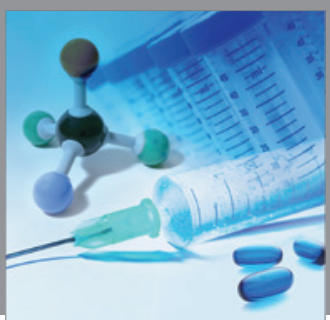

International Journal of

Medicinal Chemistry

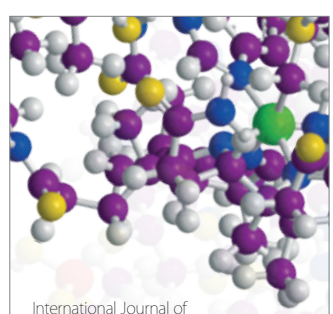

Carbohydrate Chemistry

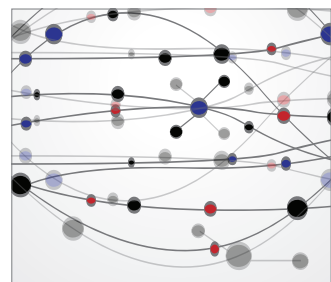

The Scientific World Journal
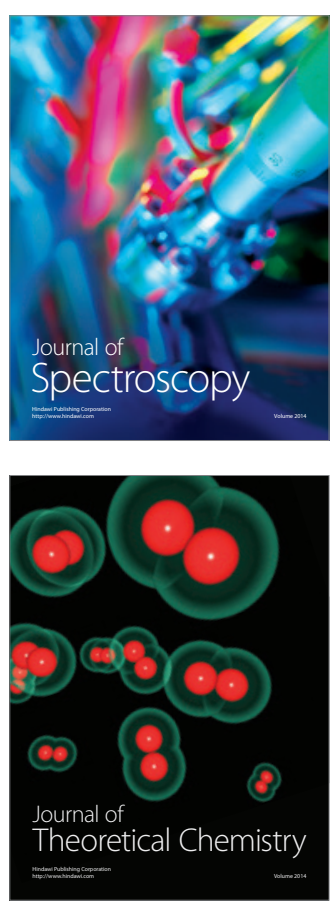
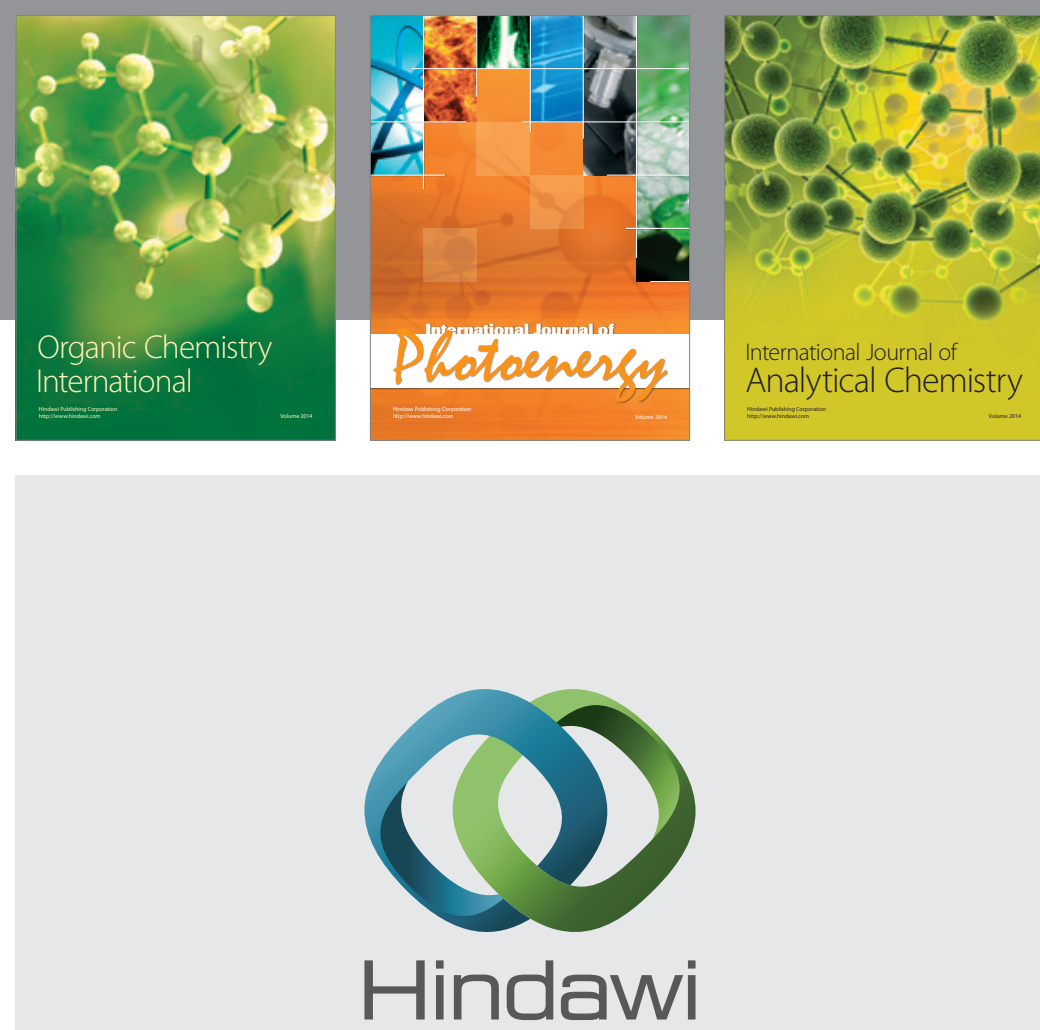

Submit your manuscripts at

http://www.hindawi.com
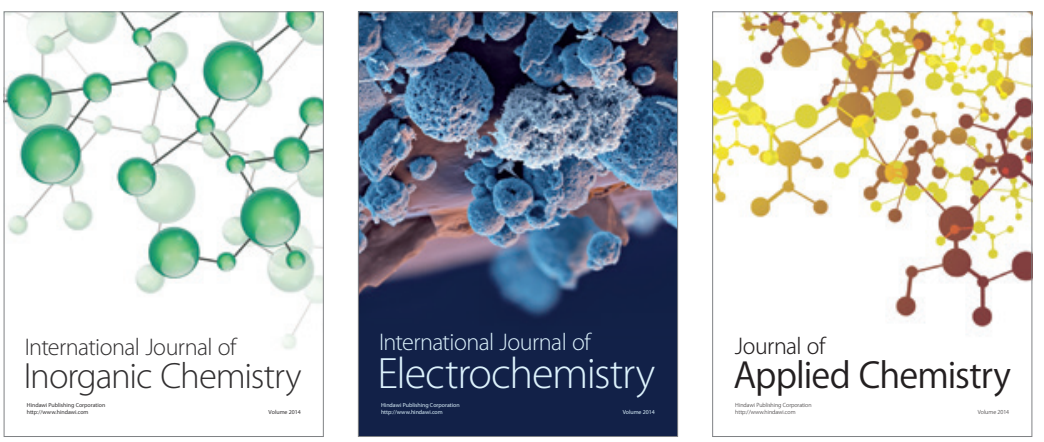

Journal of

Applied Chemistry
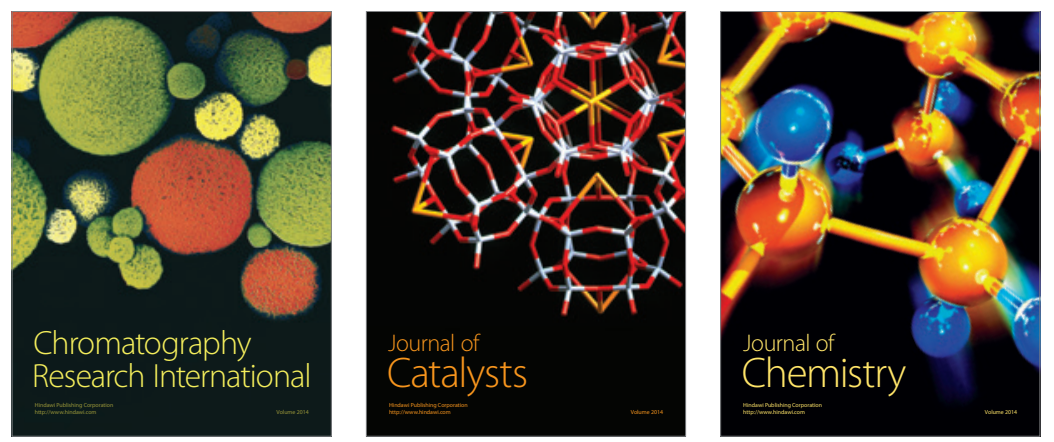
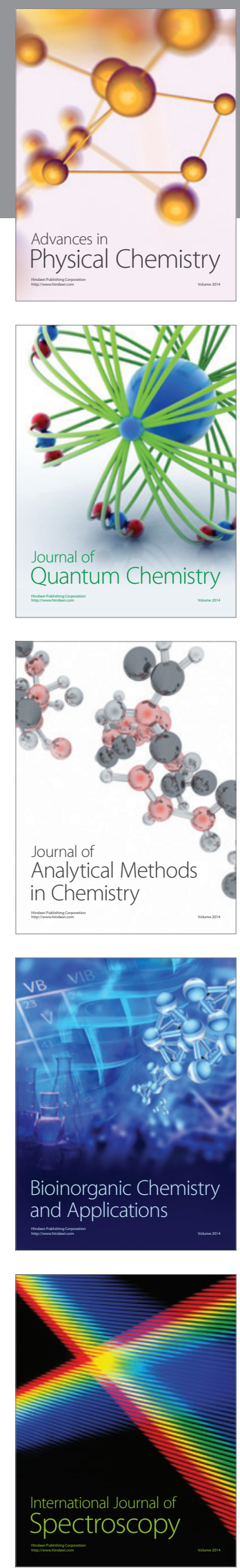